\title{
Investigation of the possible influence of Urbanization on Rainfall Variability over Nairobi City, Kenya
}

\author{
Victor Ongoma $^{1,2, *}$, Sheilla Aoko Otieno ${ }^{3}$ and Augustine Omondi Onyango ${ }^{1,4}$ \\ ${ }^{1}$ School of Atmospheric Sciences, Nanjing University of Information Science and \\ Technology, Nanjing, Jiangsu, 210044, P.R. China (*victor.ongoma@gmail.com) \\ ${ }^{2}$ Department of Meteorology, South Eastern Kenya University \\ ${ }^{3}$ Department of Mathematics, University of Nairobi \\ ${ }^{4}$ Kenya Meteorological Society
}

\begin{abstract}
The objective of the study was to investigate the possible effect of urbanization on rainfall variability over Nairobi City, Kenya. The daily rainfall and wind datasets for last 30 years were sourced from Kenya Meteorological Department while the monthly land albedo was obtained from Moderate-resolution Imaging Spectrometer (MODIS). The data was subjected to homogeneity test by using Short-Cut Bartlett test. Wind variation, rainfall trend and spatial distribution of rainfall were performed by using Wind Rose Plot (WRPLOT) View software, Mann-Kendall test and surfer respectively in the study. The results show that the dominant winds over the study area are easterlies. Higher rainfall is experienced on the western part of area as compared to the eastern side of the city. The reducing albedo over the city is a good indicator that the city is getting urbanized. The intensity of wet events is higher than dry events, characterized by high positive anomaly values. The number of rainy days is decreasing while the total rainfall is increasing in the study area. The study also reveals an increase in total rainfall with decrease in the number of rainy days. Land albedo can only explain less than 10 percent change in rainfall over the city. There remains need for further research employing higher resolution and long time data sets to ascertain the causes of the observed changes of rainfall over the city.
\end{abstract}

Keywords: Albedo, Nairobi, Rainfall, Urbanization, Nairobi, Kenya.

\section{INTRODUCTION}

Rainfall is the weather element of maximum significance for the Kenya, with its extreme occurrences resulting in droughts and floods. The events often associated with food, energy and water shortages, loss of life and property, and many other socio-economic disruptions (Ogallo and Oludhe, 2009). Urbanization process is mainly driven by human activities; it changes the land use of an area thus altering local and regional climate (Unger, 1999; Oke, 1982). The process is also known to remove the natural vegetation and replace it with nonevaporating and non-transpiring surfaces such as concrete (García-Cueto et al., 2009). Climate is altered by urbanization through release and retention of more energy; greenhouse gases, concentration of suspended dust and other pollutants into the atmosphere (Figuerola and Mazzeo, 1998). One of the common problems of urbanization that has been studied widely is Urban Heat Island (UHI). It is a condition whereby the temperature over the city is 
normally enhanced as compared to the neighboring environs (Oke, 1982; Kalnay and Cai, 2003).

One of the indicators of urbanization is population. Today, approximately 40 per cent of the one billion people living in Africa lives in urban areas. The urban population in Africa doubled from 205 million in 1990 to 400 million in 2010, and by 2050, it is expected that this would have tripled to 1.23 billion (UNEP and UN Habitat, 2011). Kenya is experiencing rapid urbanization growth just like many other developing countries in Africa (UN-Habitat, 2008).

The climate of Nairobi City as mentioned in Makokha and Shisanya (2010) and reported by other studies (e.g. Okoola, 1996; Nakamura, 1966), is predominantly equatorial climate, mainly being influenced by the altitude. The mean annual temperature value is $19{ }^{\circ} \mathrm{C}$ while the annual rainfall varies from $800 \mathrm{~mm}$ in the east to over $1000 \mathrm{~mm}$ in the west. Relative humidity is higher in the morning (over 80\%) and lower in the afternoon (below $40 \%$ ), while sunshine duration varies from 4 to 9 hours per day. According to studies (e.g. Opijah et al., 2007; Ongoma et al., 2013a), the predominant easterlies over Nairobi are linked to observed rainfall occasioned by moisture inflow into the country from the neighbouring Indian Ocean. The industrial area on the eastern side of the Nairobi city has expanded and new industrial zones have come up leading to increased air pollution within the city. The ever-increasing number of motor vehicles in the city leads to air pollution especially during peak traffic hours. Muthoka and Ndegwa (2014) studied the dynamism of land use changes on surface temperature over Nairobi City using Normalized Difference Vegetation Index (NDVI) as an indicator of urbanization. The study found out that urbanization was taking place with forest, plantations, shrubs, grassland and bare land changing to built-up, characterized by reducing NDVI.

The effects of urban processes on precipitation have been widely investigated. However, the reports from earlier studies are not always consistent. In most studies, an increase in rainfall in regions downwind of urban areas, with the increase as high as 25 per cent in some areas has been reported (Shepherd et al., 2002; Mote et al., 2007; Hand and Shepherd, 2009). Changnon (1968) noted evidence of warm seasonal rainfall increases of 9-17 per cent downwind of major cities. The Metropolitan Meteorological Experiment (METROMEX) study carried out in 1970s in the United States suggested that the urban effects contribute to precipitation enhancement by 5 to 25 percent, in a distance of $50-75 \mathrm{~km}$ downwind of the urban center (Changnon, 1981; Fujibe, 2003; Bornstein, and LeRoy, 1990). Rainfall enhancement downwind of an urban setting was also observed by the Tropical Rainfall 
Measuring Mission (TRMM) between the years 1998 and 2000 in the cities of America. It was noted that monthly rainfall was enhanced by up to 28 percent to an extent of 30 to $60 \mathrm{~km}$ downwind of the cities; this was documented by Shepherd et al., (2002). These observations were explained by the intensified heating of the city in comparison to the surrounding area that leads to an increased instability and convective activities over downwind areas of the city.

According to Changnon (1978), urbanization influence makes the process of precipitation more active in any kind of unstable condition conducive for natural precipitation occurrence. Shem and Shepherd (2008) quantified the relative changes in sensible and latent heat fluxes as a function of urban land cover for Atlanta. The study also noted enhanced mesoscale low level convergence in urbanized centres owing to UHI (Bornstein and Lin, 2000; Jiang and Liu, 2007). However, some studies have reported the contrary as a result of evaporation (Zhang et al., 2009). Similar research eluded the findings to a complexity of aerosol effects (Rosenfeld et al., 2007; Rosenfeld and Woodley, 2003).

According to past studies, the complicated urban surface geometries reduce the surface albedo over urban areas, this arises following multiple reflections and trapping of radiation with the canyon spaces (Arnfield, 1982). Oke (1987) measured urban albedo and found it to range from 0.08 to 0.20 in United States' cities in late $1980 \mathrm{~s}$.

The aim of the study is to investigate possible the effect of urbanization on rainfall variability in the study area. The findings of this work acts as a valuable tool in future related studies and solving the potential problems from rainfall, if well applied.

\section{METHODOLOGY}

\subsection{Study Area}

The city of Nairobi is Kenya's capital. It is confined within latitude of $1^{\circ} 9^{\prime} \mathrm{S}-1^{\circ} 28^{\prime} \mathrm{S}$ and longitude of $36^{\circ} 4^{\prime} \mathrm{E}-37^{\circ} 10^{\prime} \mathrm{E}$, it covers an area of $684 \mathrm{~km}^{2}$. The city is located $140 \mathrm{~km}$ to south of the Equator and $480 \mathrm{~km}$ from the Indian Ocean. The altitude of Nairobi ranges from an average of $1500 \mathrm{~m}$ in the east to approximately $1900 \mathrm{~m}$ in the west (Fig 1). According to the most recent population census, the city is a home to about 3.1 million people (KNBS, 2010). Nairobi was established in 1899 as a railway supply depot. In 1934, Nairobi was upgraded into a municipality, and it acquired city status in 1950. Initially, Nairobi covered an area of $18 \mathrm{~km}^{2}$, there have been several boundary expansions. In 1927, the town area was extended to cover $78 \mathrm{~km}^{2}$ and in 1963, it was extended further to cover an area of approximately $680 \mathrm{~km}^{2}$. 
The city has relatively well-developed infrastructure, including a modern airport and commercial centres have led to a very rapid expansion of the city since 1979. As mentioned in Muthoka and Ndegwa (2014), the city has witnessed urban explosion in recent years with conversions of pervious surfaces to impervious surfaces.

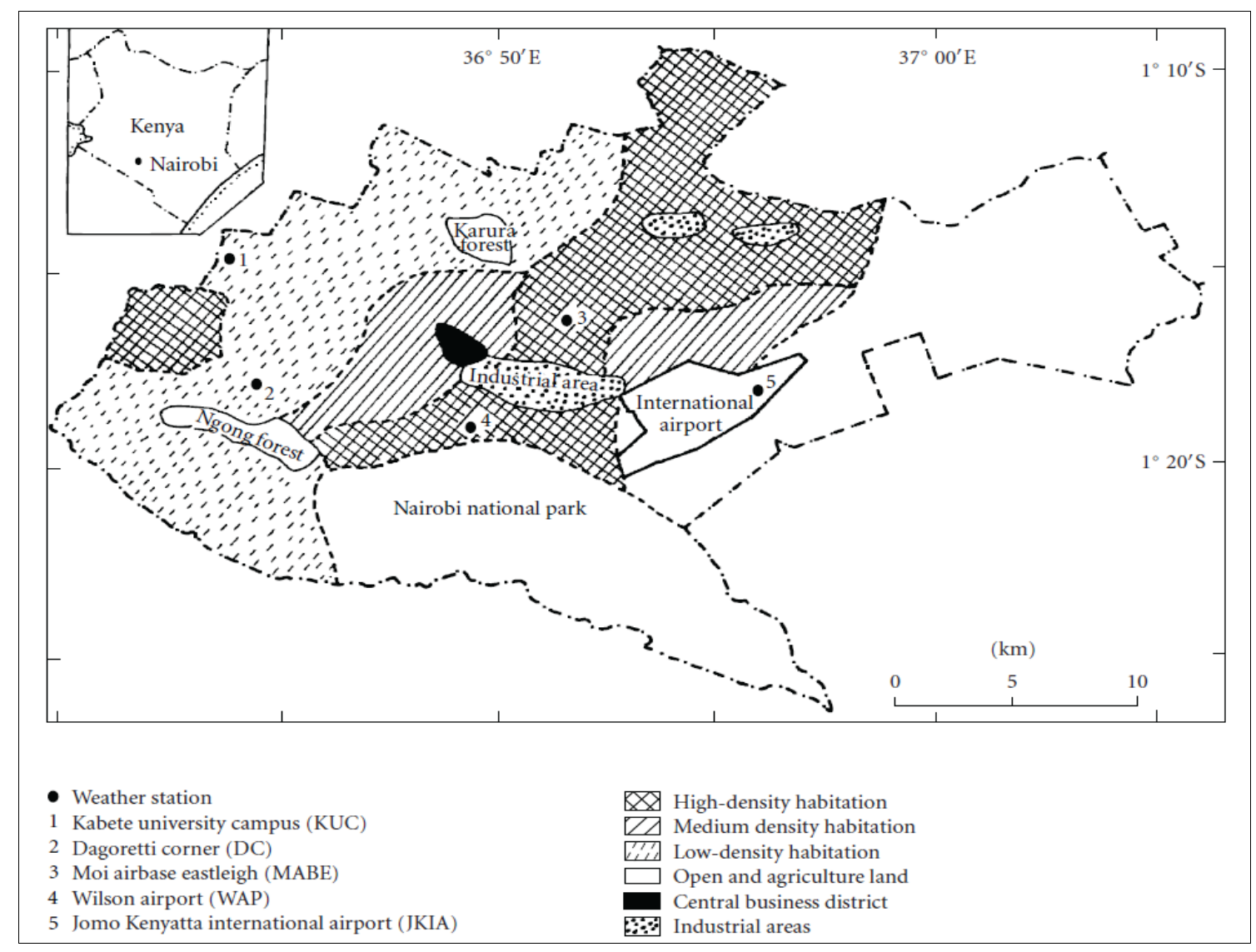

Figure 1. Land use and positions of permanent weather stations in Nairobi (Source: Makokha and Shisanya, 2010).

The eastern wing of the city is a home to industries, it is popularly known as 'Industrial Area'. The city's main dumping area, formally known as 'Dandora Municipal waste dumping site' is located to the east of Nairobi. The site, sitting on a 30 acre piece of land is situated approximately 8 kilometers away from the city and serves almost the entire Nairobi city.

Table 1. Meteorological Stations used in the Study.

\begin{tabular}{|lcccc|}
\hline Station & Longitude & Latitude & \multicolumn{2}{c|}{ Data length } \\
\cline { 4 - 5 } & $\left({ }^{\circ} \mathbf{E}\right)$ & $\left({ }^{\circ}\right)$ & From & To \\
\hline Moi Air Base & 36.87 & 1.27 & 1975 & 2008 \\
\hline Dagoretti Corner & 36.75 & 1.30 & 1960 & 2010 \\
\hline Wilson & 36.82 & 1.32 & 1975 & 2010 \\
\hline Jomo Kenyatta International Airport & 36.92 & 1.32 & 1975 & 2010 \\
\hline Kabete Agromet & 36.75 & 1.27 & 1975 & 2008 \\
\hline
\end{tabular}




\subsection{Data and Methods}

\subsubsection{Data}

The daily rainfall and wind speed and direction data for 30 - 40 years was sourced from Kenya Meteorological Department (KMD) (Table 1).

Observed mean hourly wind speed and corresponding wind direction data spanning from 1991 to 2010 was utilized.

Land albedo was obtained from Moderate-resolution Imaging Spectrometer (MODIS). The monthly data spanning from August 2002 to December 2005 was acquired at a resolution of $500 \times 500 \mathrm{~m}$. The length of the data was limited by data availability.

The climate data was passed through a quality control procedure. In view of the data quantity and length, the study employed Short-Cut Bartlett Test for the homogeneity test of the data.

Short-Cut Bartlett Test method is useful for the test of constancy of variability in a time series (Aesawy and Hasanean, 1998), it is applied by dividing the series into $k$ equal sub periods, where $k>2$. In each of these sub-periods, the sample variance $S_{k}$ is given by equation 1 .

$\mathrm{S}_{\mathrm{k}}^{2}=\frac{1}{\mathrm{n}}\left[\sum \mathrm{x}_{\mathrm{i}}^{2}-\frac{1}{\mathrm{n}}\left(\sum \mathrm{x}_{\mathrm{i}}\right)^{2}\right]$

Where, the summations range over the $n$ values of the series in the sub-period $k$. The analyses in the study had 6 sub-periods. The largest and smallest values of $S_{k}^{2}$ are the selected and denoted as $S_{\max }^{2}$ and $S_{\min }^{2}$ respectively. The 95 per cent significance points for the ratio $S_{\max }^{2} /$ $\mathrm{S}_{\min }^{2}$ is obtained by comparing this ratio with the values in F-distribution table $\mathrm{F}_{0.95}$. The null hypothesis is rejected if the F- value calculated value is less than F-tabulated value.

Using rainfall observations, the study identified all the rain events (with near-surface rain rate $\geq 0.1 \mathrm{~mm} /$ day). This was in conformity with Martin-Vide and Gomez (1999) who used 0.1 $\mathrm{mm}$ with the basis that it is the usual precision of rain-gauges. A rainy day was thus classified using equation 2 .

if $(x) \geq 0.1 \mathrm{~mm}$, "rainy"

Where, $x$ is the rainy event.

\subsubsection{Interannual Rainfall Variability}

The standardized rainfall anomaly $(Z$ ) was used to categorize dry and wet years, it is computed as expressed in equation 3 .

$$
Z=\frac{X-\bar{X}}{S_{d}}
$$


Where, $X$ is the observed annual rainfall, $\bar{X}$ is the long term mean annual rainfall and $S_{d}$ is the annual rainfall standard deviation.

The value of $Z$ provides immediate information about the significance of a particular deviation from the mean. The approach was recently used successfully by Ogwang et al. (2012) when carrying out diagnosis of September - November drought and the associated circulation anomalies over Uganda.

\subsubsection{Rainfall Trend Analysis}

The Mann-Kendall rank statistic was used to detect abrupt changes in the weather parameters. The test is appropriate for analysis of series which show significant trend to locate the period from which the trend is demonstrated (Sneyers, 1990). This method was successfully applied by Makokha and Shisanya (2010) to examine the long-term changes in mean annual surface temperature in Nairobi City.

Mann-Kendal rank statistic is considered the most appropriate for analysis of climatic changes in climatological time series for the detection of a climatic discontinuity (Chrysoulakis et al., 2002).

The test uses the ranks $y_{i}$ of all the terms, $x_{i}$ in a series under analysis when arranged in increasing order of magnitude. For each element $y_{i}$, the number $n_{i}$ of element $y_{i}$ preceding it $(i>j)$ is calculated such that $\mathrm{y}_{i}>\mathrm{y}_{j}$. The test statistic is given by equation 4 .

$\mathrm{t}_{i}=\sum_{i} n_{i}$

and its distribution function under the null hypothesis is asymptotically normal, with mean (equation 5).

$E\left(t_{i}\right)=\frac{\mathrm{n}(\mathrm{n}-1)}{4}$

and variance (equation 6);

$\operatorname{Var}\left(t_{i}\right)=\frac{\mathrm{n}(\mathrm{n}-1)(2 \mathrm{n}+5)}{72}$

In the absence of any assumptions regarding the existence of a trend in a given direction, the test is correct only if its two-sided form is adopted, that is if the null hypothesis is rejected for large values of $u\left(t_{i}\right)$, given by equation 7 .

$u\left(t_{i}\right)=\frac{\left[\mathrm{n}\left(\mathrm{t}_{\mathrm{i}}\right)-\mathrm{E}\left(\mathrm{t}_{\mathrm{i}}\right)\right]}{\sqrt{\operatorname{Var}\left(\mathrm{t}_{\mathrm{i}}\right)}}$ 
In these conditions, a probability $\alpha_{1}$ (equation 8) is determined using a standard normal distribution table such that;

$$
\alpha_{1}=\mathrm{P}\left(|\mathrm{u}|>\left|\mathrm{u}\left(\mathrm{t}_{\mathrm{i}}\right)\right|\right)
$$

The null hypothesis is accepted or rejected at the level $\alpha_{0}$ depending on whether $\alpha_{1}>\alpha_{0}$ or $\alpha_{1}<\alpha_{0}$. When the values of $u\left(t_{i}\right)$ are higher (in absolute value) than 1.96 , an increasing or decreasing trend can be observed depending on whether $u\left(t_{i}\right)$ is positive or negative. When a series shows a significant trend we wish to locate the start of the phenomena by means of a sequential analysis. In this case, it can be usefully extended to the reversed series. Therefore, we calculate the number $n_{i}$ of $y_{i}$ terms for each $y_{i}$ term such that $y_{i}>y_{j}$ with $i<j$, which gives a check on the first calculation, given equation 9, and further explained by equation 10 .

$n_{i}{ }^{\prime}=y_{i}-1-n_{i}$

So that;

$\mathrm{i}^{\prime}=(N+1)-1$

Where, $N$ is the total number of observations in the series.

Therefore, the values of $u^{\prime}\left(t_{i}\right)$ for the reversed series can be calculated similar to $u\left(t_{i}\right)$. In the absence of any trend in the series, the graphical representation of $u$ and $u$ in terms of $i$ generally gives curves which overlap several times.

\subsubsection{Spatial Analysis of Rainfall and Wind}

Contouring and surface modeling package (Surfer version 8) was used to produce rainfall map over the city. Gridded data of deviations from arithmetic mean rainfall over the city was used to produce contour maps.

Wind Rose Plot View software (WRPLOT version 7) was used to analyze the winds over the city. The WRPLOT gives wind rose and wind rose statistics. A wind rose depicts the frequency of wind directions and wind speed for a given location and time span. The WRPLOT View software is useful in approximation of the wind resultant vector. The software has been successfully used by previous studies (Abdalla et al., 2013; Droppo and Napier, 2008). Abdalla et al. (2013) used the software to determine the optimum airport runway orientation for different regions in Egypt, based on wind characteristics. 


\section{RESULTS AND DISCUSSION}

\subsection{Rainfall Homogeneity}

The result of homogeneity test is presented in figure 2 . Since the test statistic is less than the critical value, the null hypothesis at the 0.05 significance level is accepted; that the data is homogeneous.

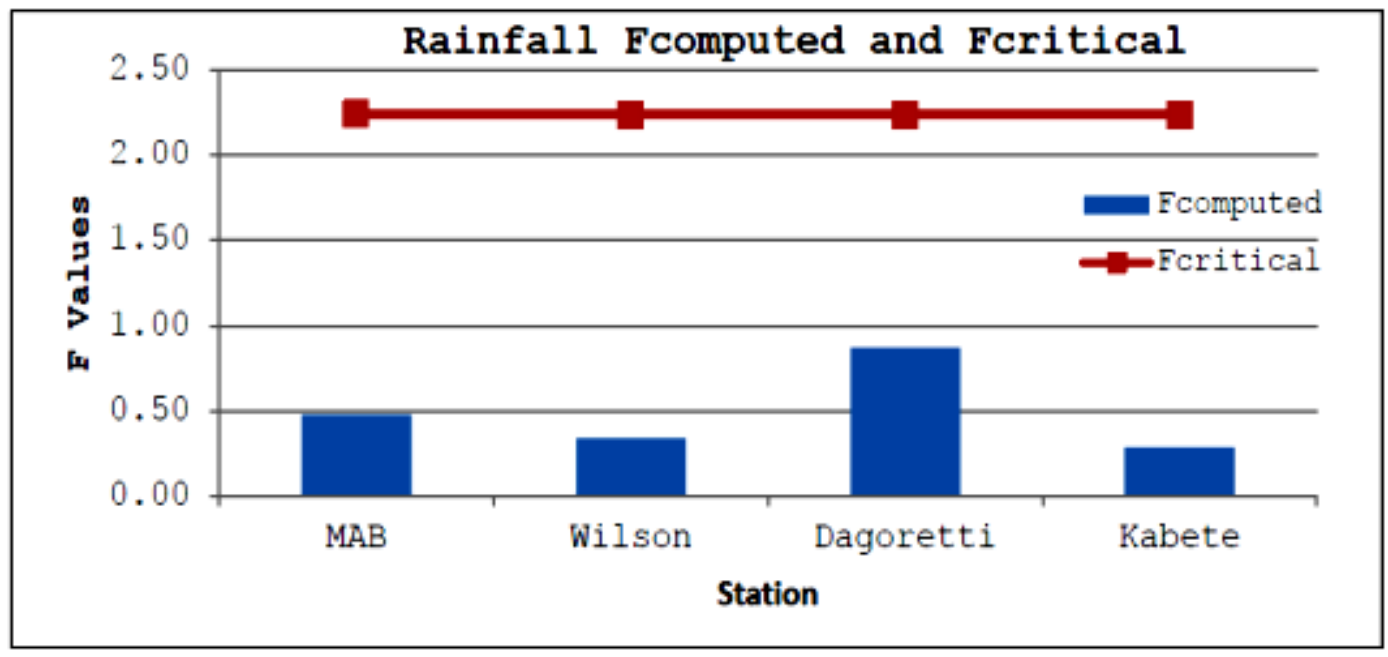

Figure 2. Rainfall Homogeneity Test of rainfall data (Fcomputed is the test statistic and Fcritical is critical value).

According to Peterson et al. (1998), a set of homogenous spatio-temporal climate time series has variations attributed to variations in weather and climate. The data was thus recommended and used for analysis to achieve the objectives of the study.

Earlier studies over Nairobi (e.g. King'uyu et al., 2011; Indeje et al., 2000) found significant station to station homogeneity. King'uyu et al. (2011) used mass curves to test maximum temperature and rainfall data homogeneity using RClimdex. The study showed that generated daily temperature range for Dagoretti Corner was homogeneous. This may be attributed to the dominance of large-scale weather systems that may be responsible for the spatial homogeneity of rainfall over the country.

\subsection{Urban Growth Trend}

Land surface reflectivity (albedo) was used to assess urban development. Albedo is an indicator of the land surfaces activities; the different types of land cover have different extents of reflectivity to incoming solar radiation. The land use changes lower the albedo of urban areas compared to vegetated areas. Nairobi city has experienced varying rates of urbanization with time from August 2002 to March 2005 as indicated by the general decreasing trend of the reflectivity with time (Fig 3). The decrease in albedo over the city is 
partly linked to the observed increasing surface temperature over the city (Ongoma et al., 2013b).

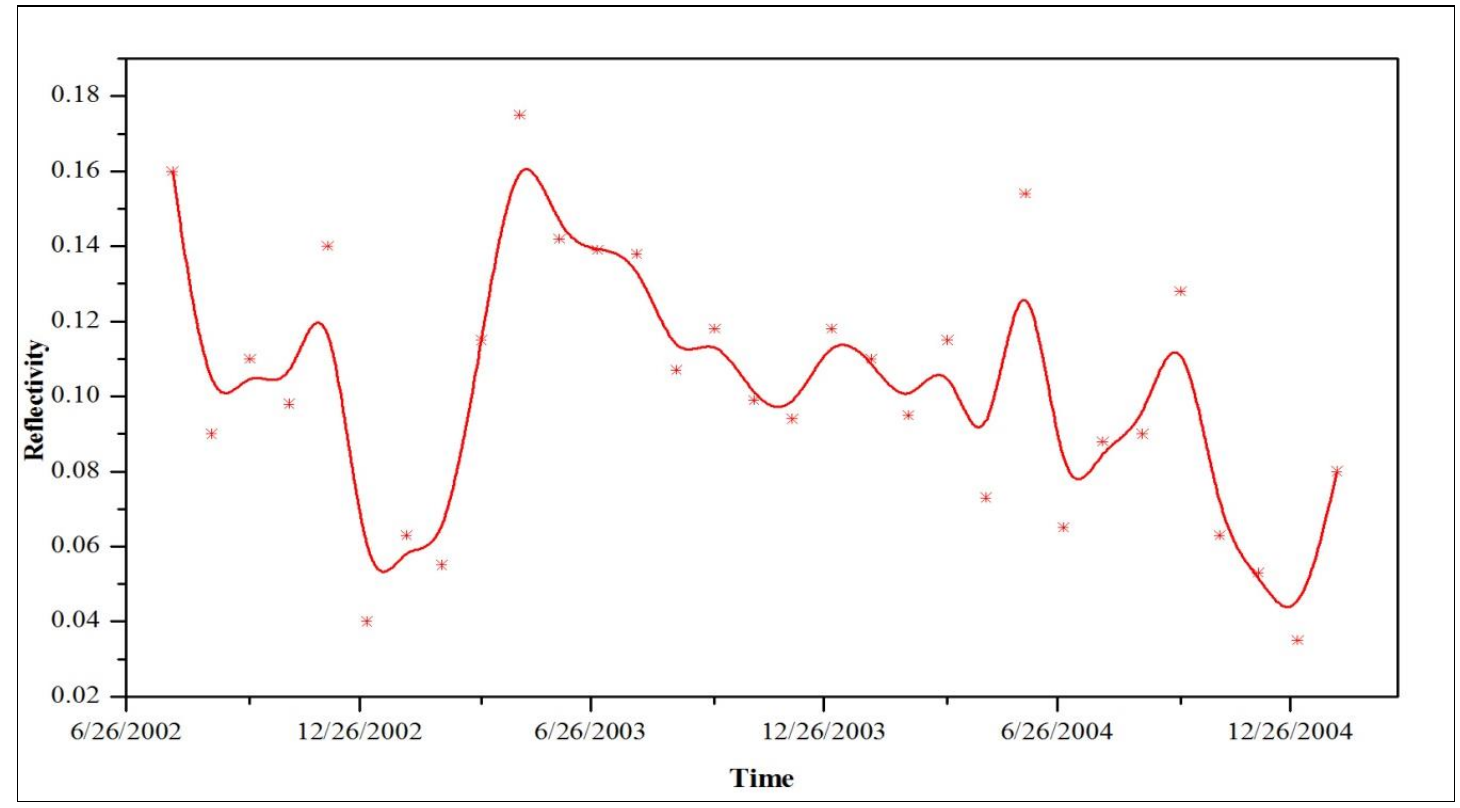

Figure 3. Land Surface Reflectivity over Nairobi City from August 2002 to March 2005.

The albedo values over the city were mainly confined between 0.04 and 0.16 . The reflectivity values closely agree with the findings by Oke (1987), whose study measured values of albedo in urban areas and found out that they ranged from 0.10 to 0.27 , with a mean of about 0.15 . Similarly, Taha (1994) performed low altitude flights over the Los Angeles Basin and found that the highest albedo in that area was 0.20 . He also found that much of the urbanized basin had an albedo between 0.12 and 0.16 . The reduction in albedo has an effect of increasing evaporation/evapo-transpiration and consequently rainfall over a given locality. Frey et al. (2007) recorded similar results in Abu Dhabi and Dubai, United Arab Emirates.

\subsection{Rainfall Variability and Trend}

Figure 4 presents inter-annual rainfall variability over Nairobi City for the period of 30 years, 1980 to 2010 . The dry and wet years were chosen basing on the standard deviation being $\leq-1$ (for dry year) and $\geq+1$ (for wet year) as used by Okoola (1999) when carrying out a diagnostic study of the Eastern Africa monsoon circulation during the northern hemisphere spring season. The standardized rainfall anomaly shows two wet years in the last half of the study period, 2001 - 2010. It is evident that throughout the period of study that the intensity of wet events is higher than dry events, characterized by high positive anomaly values. There is observed increment in the number of rainy days in the earlier years; $1969-1983$ and 
decrease thereafter; 1984 to 2008 (Fig 5), the change is however insignificant. Figure 5 shows test results of the sequential Mann-Kendall test for the number of rainy days.

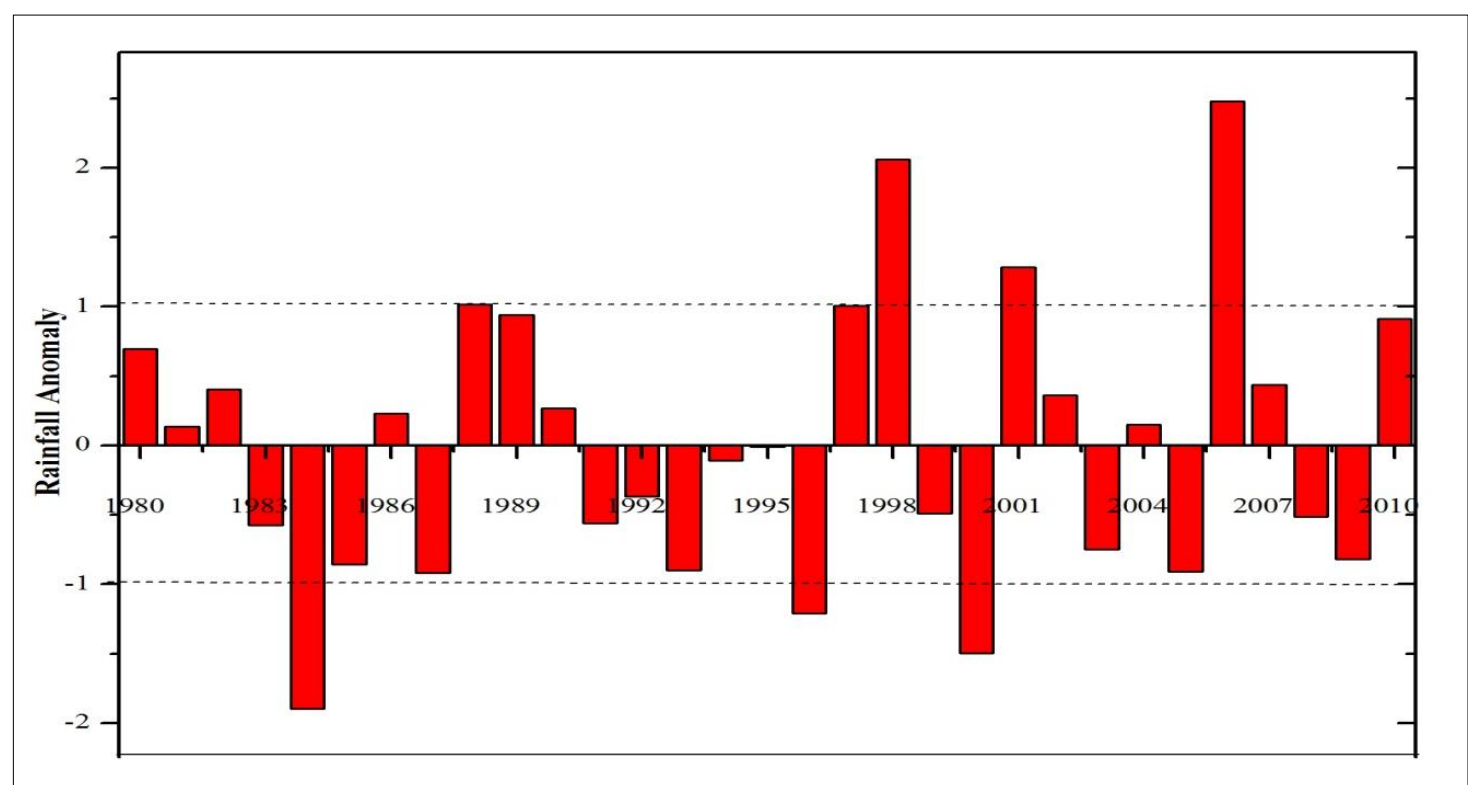

Figure 4. Inter-annual rainfall variability over Nairobi City for the period of 1980 and 2010.

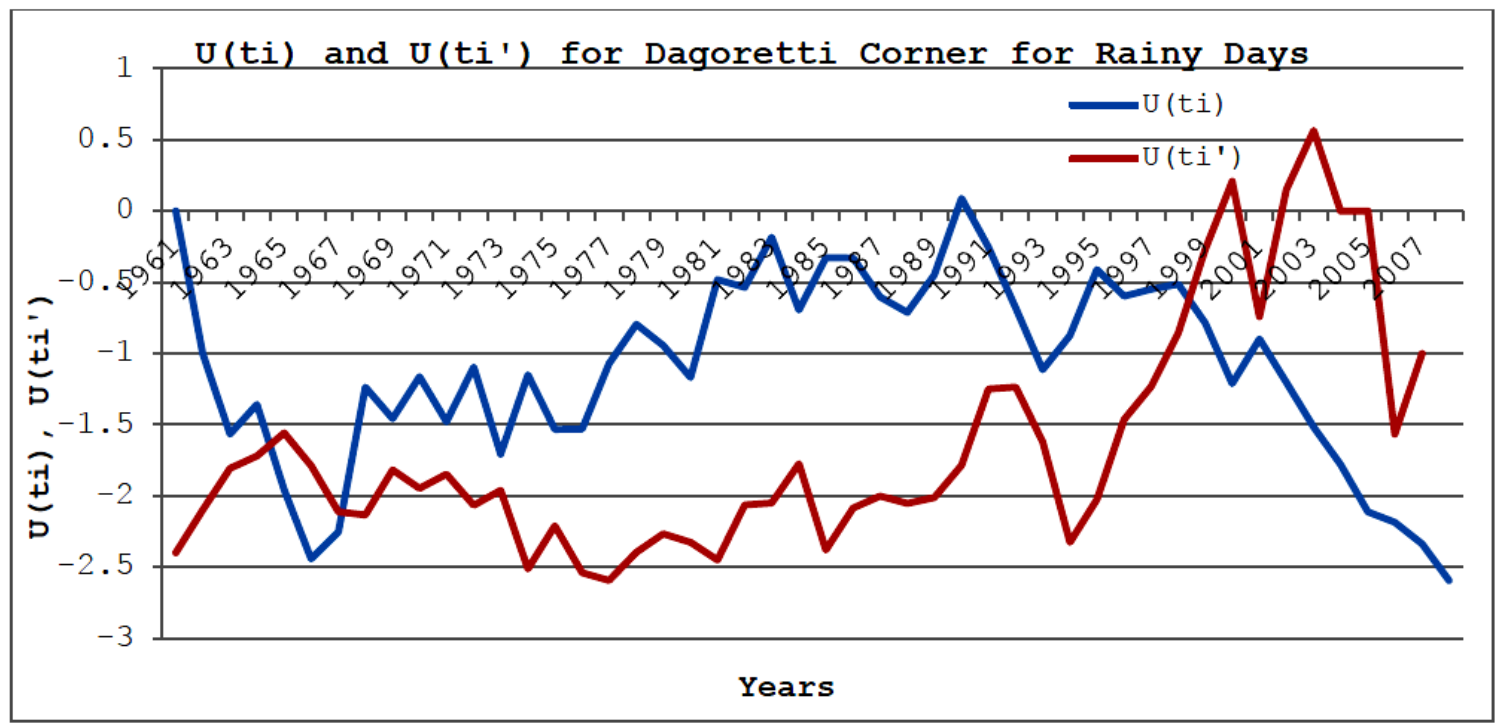

Figure 5. Mann-Kendall test for Dagoretti Corner Rainy Days, $U(t i)$ is the forward sequential statistic and the $U\left(t i^{\prime}\right)$ is the backward sequential statistic.

A study by Rosenfeld and Woodley (2003) showed a reduction in the number of rainy days in urban centres, linking the observation to pollution aerosols that initiate condensation resulting in large concentration of small cloud droplets that in turn suppresses the drop coalescence.

There is observed significant trend of total rainfall increase from early 1990s (Fig 6). The enhancement could be attributed to UHI. The island creates a low pressure centre in the city 
thus enhancing lifting of air especially in the afternoon leading to deep cloud formation resulting in intense rainfall.

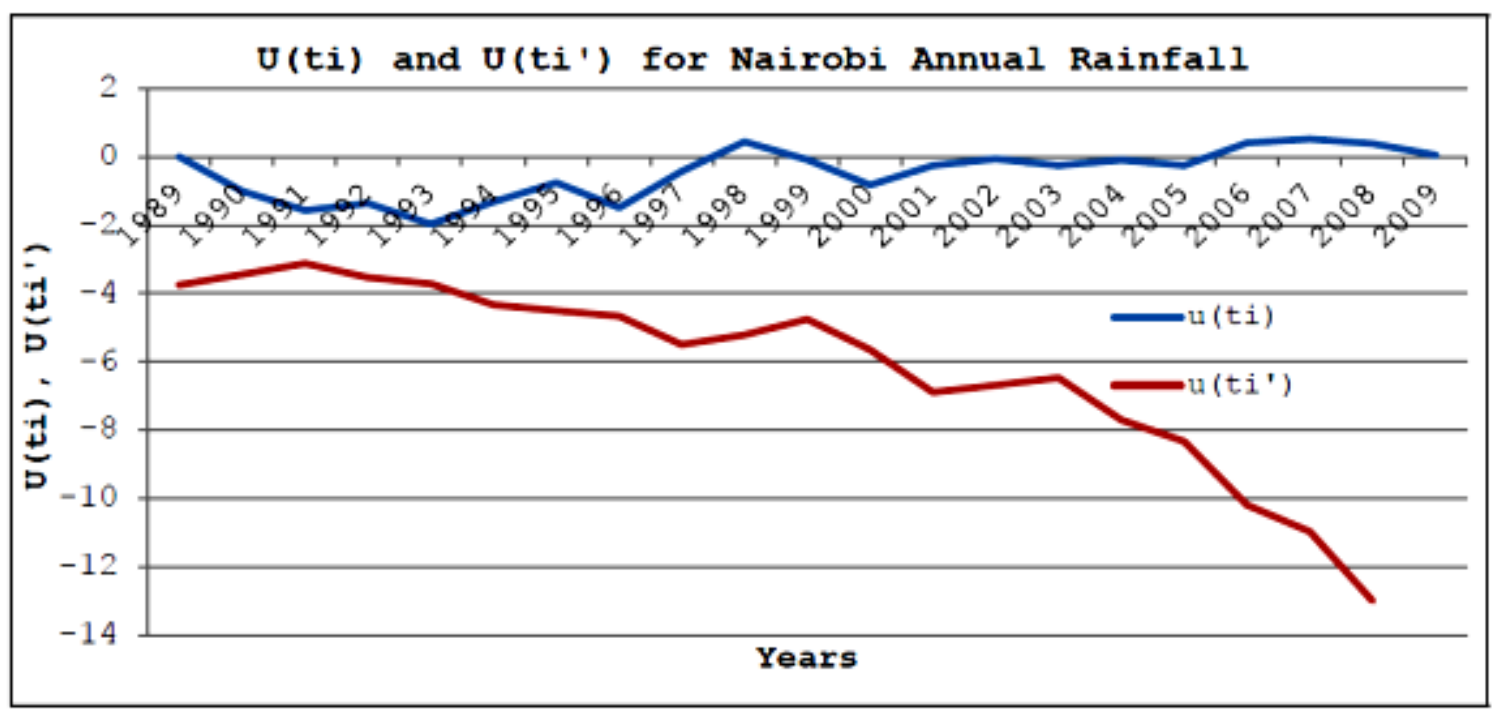

Figure 6. Mann-Kendall Test for total Rainfall of Nairobi, $U(t i)$ is the forward sequential statistic and the $U\left(t i^{\prime}\right)$ is the backward sequential statistic.

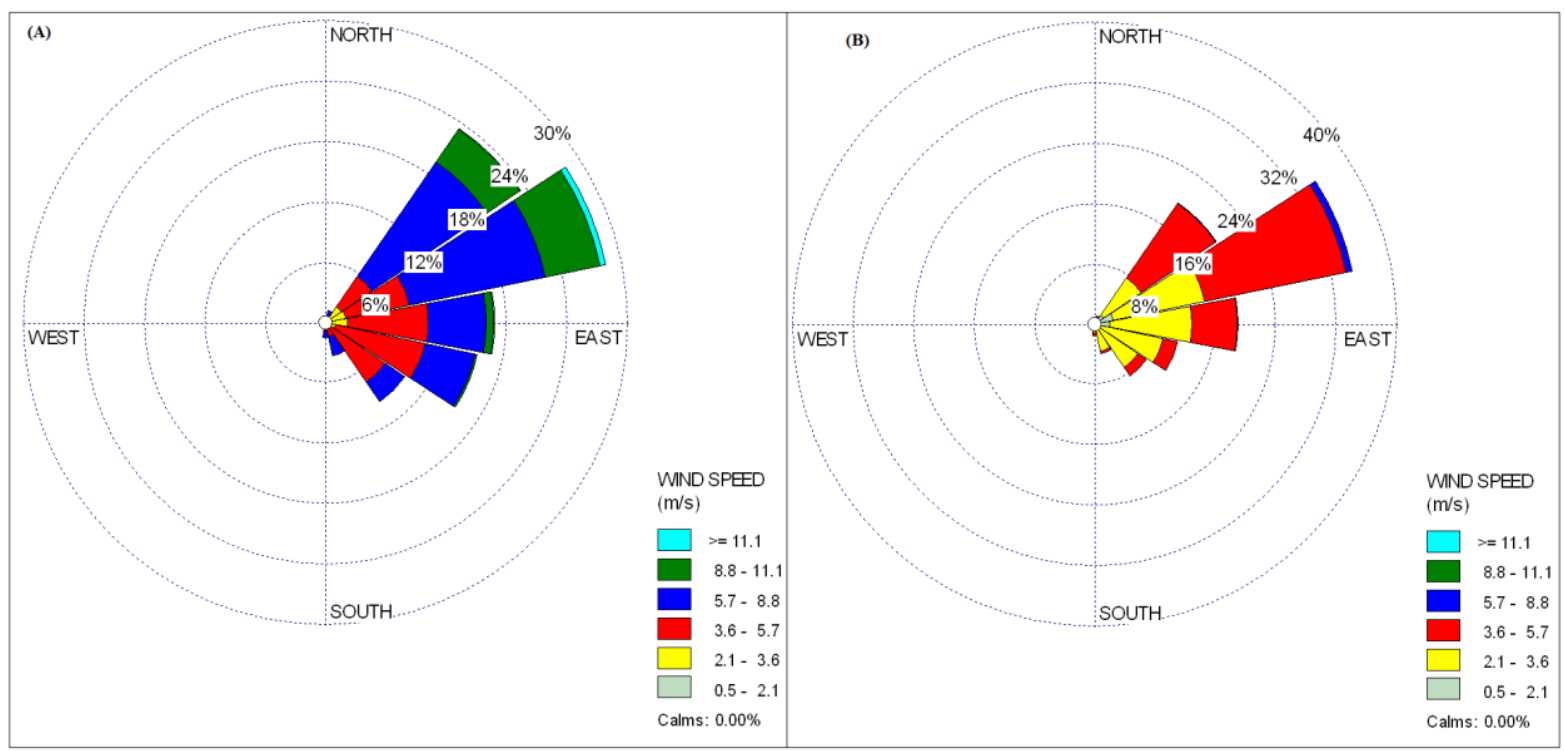

Figure 7. Wind Roses of Nairobi City (A) 1991 - 2000, (B) 2001 -2010.

There is however no noticeable abrupt changes in annual total rainfall. The predominant winds annually over Nairobi are the easterlies. The winds are associated with precipitation occasioned by moisture inflow into the country from the Indian Ocean. The wind thus transports pollutants from the eastern zone of the city; which is mainly the industrial area, to the western parts of the city (Fig 7). 
The highest positive rainfall deviation from the total rainfall over Nairobi was recorded on the western part of the city (Fig 8).

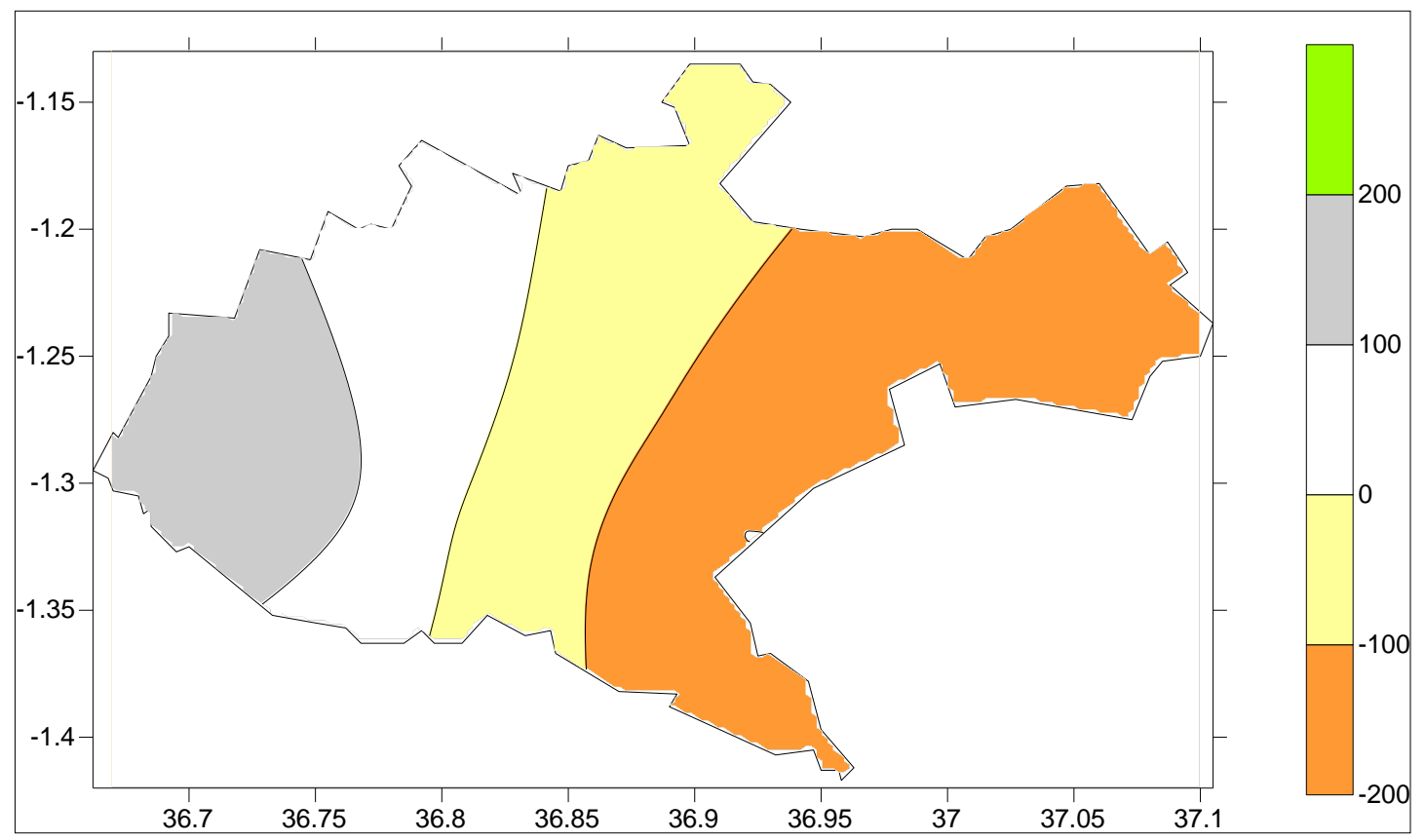

Figure 8. Spatial distribution of rainfall deviations from the mean rainfall over Nairobi City, from $1975-2010$.

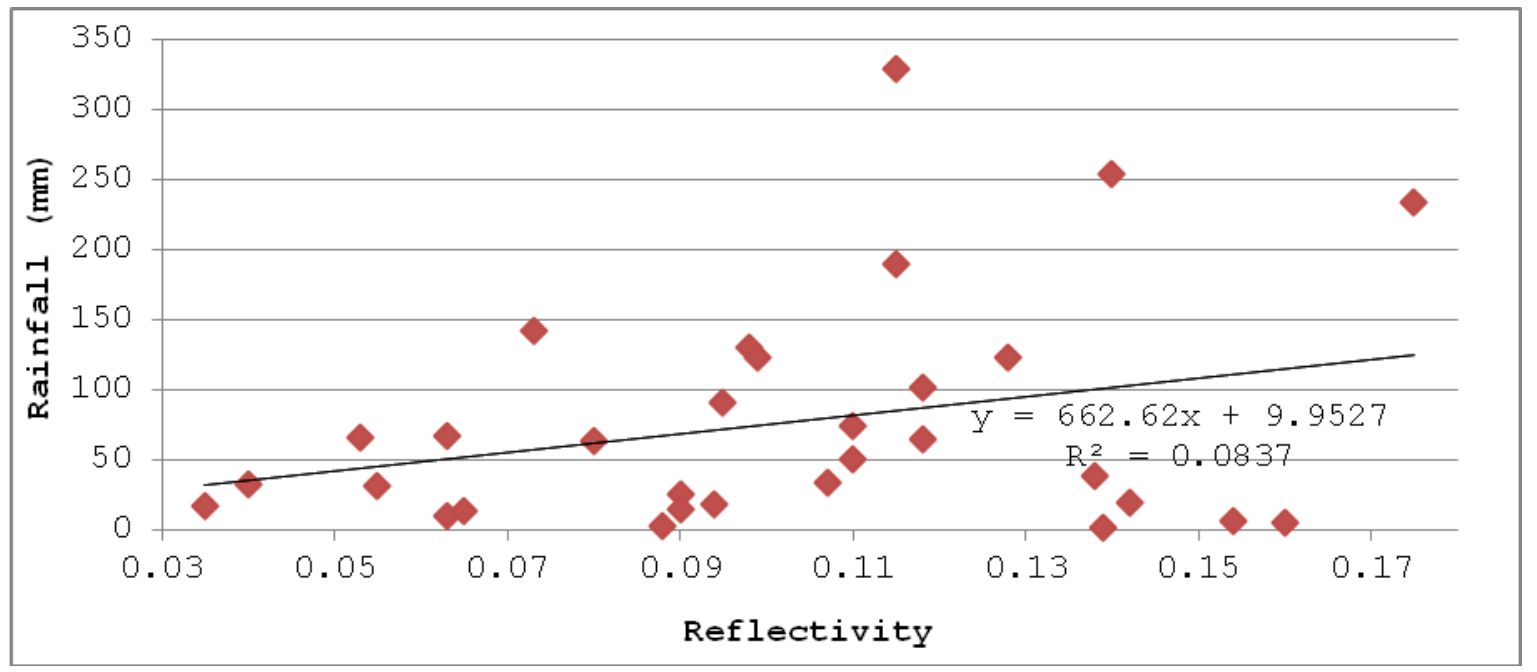

Figure 9. Regression of monthly Rainfall and Total sky Land Surface Reflectivity over Nairobi.

This can be attributed to the fact that the western part of the city is on the downwind side and thus it has high concentration of pollutants, mainly aerosals from anthropogenic emissions. The emissions are condensation nuclei thus enhancing cloud formation leading to more rainfall observed in the western part of the city. The western side of the city is at a higher 
altitude as compared to the eastern side, thus it is likely to serve as a lifting mechanism for air flowing from the east of the city. This facilitates cloud formation, increasing the probability of occurrence of frequent and intense rainfall.

\subsection{Urbanization - Rainfall Relationship}

Figure 8 shows a positive relationship between total sky land surface reflectivity and monthly rainfall over the city. The positive relationship indicates that monthly rainfall reduces with reduction in albedo. This is contrary to the observation in figure 6 , where there is significant increase in total rainfall from early 1990s. Most studies (e.g. Shepherd et al., 2002; Mote et al., 2007) have equally reported an increase in rainfall in regions downwind of urban areas with the increase as high as 25 per cent in some areas. The observed results in figure 9 however can be as a result of short time span of the data considered owing to availability of data.

The coefficient of determination of rainfall by reflectivity over Nairobi is 8.3 per cent. Thus, less than 10 per cent change in monthly rainfall over city can be explained by urbanization of the city.

\section{CONCLUSION}

The study analyzed the impact of urbanization on rainfall trend over the Nairobi city, Kenya using statistical inference. The reduction in land surface reflectivity is an indicator of reduction in land cover which is associated with urbanization. The land use-land cover changes with growth of the city, reducing land cover and consequently, the land surface reflectivity. The study identified insignificant increase in the number of rainy days on the earlier years; 1969 -1983 and decrease thereafter; 1984 - 2008. The total rainfall is however observed to increase significantly throughout the study period. The observation can be attributed to anthropogenic activities in the city that increase the number of cloud condensation nuclei in the urban atmosphere necessitating rain formation. Less than 10 per cent change in monthly rainfall can be attributed to change in albedo; an indicator of urbanization. Further research should thus be conducted to ascertain the major cause of the observed changes in total rainfall. Nevertheless, the environmental implications of such rainfall modification must be incorporated in the current urban planning programs of the city. However, there should be more studies using high resolution and long term data over the city. Further studies should focus on how the rainfall modification is likely to affect the water drainage in the study area. 


\section{ACKNOWLEDGEMENTS}

The authors express his gratitude to Kenya Meteorological Department (KMD) for the provision of climatological data used in the study. Special thanks go to Nanjing University of Information Science and Technology (NUIST) for providing motivation and an enabling environment to carry out research always.

\section{REFERENCE}

Abdalla, E.S.M., Osman, M.E \& Mohamed, R.N.A.E. 2013. The optimum airport runway orientation for different regions in Egypt. Journal of Engineering Science, 41(6): $2126-2139$.

Aesawy, A.M \& Hasanean, H.M. 1998. Annual and seasonal climatic analysis of surface air temperature variations at six southern Mediterranean stations. Theoretical Applied Climatology, 61(1): 55 - 68. DOI: 10.1007/s007040050051.

Arnfield, A. J. 1982. An approach to the estimation of the surface radiative properties and radiation budgets of cities. Physical Geography, 3(2): 97-122. DOI: 10.1080/02723646.1982.10642221.

Bornstein, R \& LeRoy, M. 1990. Urban barrier effects on convective and frontal thunderstorms. Pp. 120-121. In: Extended abstracts of the fourth conference on mesoscale processes, Boulder, Co. American Meteorological Society, Boston, USA

Bornstein, R \& Lin, Q. 2000. Urban heat islands and summertime convective thunderstorms in Atlanta: Three case studies. Atmospheric Environment, 34(3): 507-516, doi:10.1016/S1352-2310(99)00374-X.

Changnon Jr., S.A. 1968. The La Porte weather anomaly - fact or fiction? Bulletin of American Meteorological Society, 49(1): 4 - 11.

Changnon Jr., S.A. 1978. Urban Effects on Severe Local Storms at St. Louis. Journal of Applied Meteorology, 17(5): 578 - 586. doi: http://dx.doi.org/10.1175/15200450(1978)017<0578:UEOSLS>2.0.CO;2

Changnon Jr., S.A. 1981. METROMEX: A Review and Summary. AMS, Meteorological Monogram, 18(40), $181 \mathrm{pp}$

Chrysoulakis, N., Proedrou, M \& Cartalis, C. 2002. Variations and trends in annual and seasonal means of perceptible water in Greece as deduced from radiosonde measurements. Toxicology Environmental Chemistry, 84(1-4): 1- 6. 
Droppo, J.G \& Napier, B.A. 2008. Wind Direction Bias in Generating Wind Roses and Conducting Sector-Based Air Dispersion Modelin. Journal Air Waste Management Association, 58(7): 913-918. DOI: http://dx.doi.org/10.3155/1047-3289.58.7.913.

Figuerola, P.I \& Mazzeo, A.N. 1998. Urban-rural temperature differences in Buenos Aires. International Journal of Climatology, 18(15):1709-1723. DOI: 10.1002/(SICI)10970088(199812)18:15<1709::AID-JOC338>3.0.CO;2-I.

Frey, C.M., Rigo G \& Parlow, E. 2007. Urban radiation balance of two coastal cities in a hot and dry environment. International Journal of Remote Sensing, 28(12): 2695-2712. DOI: $10.1080 / 01431160600993389$

Fujibe, F. 2003. Long-term surface wind changes in the Tokyo metropolitan area in the afternoon of sunny days in the warm season. Journal Meteorological Society of Japan, 81(1):141-149. DOI: http://doi.org/10.2151/jmsj.81.141

García-Cueto, O.R., Tejeda, A.M \& Bojórquez, G.M. 2009. Urbanization effects upon the air temperature in Mexicali, B. C., México. Atmósfera, 22(4): 349-365.

Hand, L.M \& Shepherd, J.M. 2009. An Investigation of Warm-Season Spatial Rainfall Variability in Oklahoma City: Possible Linkages to Urbanization and Prevailing Wind. Journal of Applied Meteorology and Climatology, 48(2): 251-269. doi: http://dx.doi.org/10.1175/2008JAMC2036.1.

Indeje, M., Semazzi, F.H.M \& Ogallo, L.J. 2000. ENSO Signals in East African Rainfall Seasons. International Journal of Climatology, 20(1): 19-46. doi: 10.1002/(SICI)1097-0088(200001)20:1<19::AID-JOC449>3.0.CO;2-0.

Jiang, X \& Liu, W. 2007. Numerical simulations of impacts on urbanization on heavy rainfall in Beijing using different land use data. Journal of Meteorological Research, 21(2): 245-255.

Kalnay, E \& Cai, M. 2003. Impact of urbanization and land-use change on climate. Nature, 423: 528-531. doi:10.1038/nature01675.

King'uyu, S.M., Kilavi, M., Omeny, P., Muigai, E \& Njogu, A.K. 2011. Climate change indices for Kenya. Journal of Meteorology and Related Sciences, 5(6): 49-55.

KNBS, 2010. Kenya Population Census, 2009. Ministry of State for Planning, National Development and Vision 2030, Government Print Press, Nairobi.

Makokha, G.L \& Shisanya, C.A. 2010. Trends in Mean annual minimum and maximum Near Surface Temperature in Nairobi City, Kenya. Advanced Meteorology, 2010, ID. 676041. doi:10.1155/2010/676041. 
Martin-Vide, J \& Gomez, L. 1999. Regionalization of peninsular Spain based on the length of dry spells. International Journal Climatology, 19(5): 537-555. doi: 10.1002/(SICI)1097-0088(199904)19:5<537::AID-JOC371>3.0.CO;2-X.

Mote, T.L., Lacke, M.C \& Shepherd, J.M. 2007. Radar signatures of the urban effect on precipitation distribution: A case study for Atlanta, Georgia. Geophysical Research Letters. 34(20). doi:10.1029/2007GL031903.

Muthoka, M.J \& Ndegwa, M.C. 2014. Dynamism of Land use Changes on Surface Temperature in Kenya: A Case Study of Nairobi City. International Journal of Science and Research, 3(4): 38-41.

Nakamura, K. 1966. City temperature of Nairobi. Journal of Geography, 75: 361 - 365.

Ogallo, L \& Oludhe, C. 2009. Climate information in decision making in the greater horn of Africa: lessons and experiences. WMO Bulletin, 58(3):184-187.

Ogwang, B.A., Guirong, T \& Haishan, C. 2012. Diagnosis of September - November Drought and the Associated Circulation Anomalies Over Uganda. Pakistan Journal of Meteorology, 9(17):11-24.

Oke, T.R. 1982. The energetic basis of the urban heat island. Quarterly Journal of Royal Meteorological Society, 108(455): 1-24. DOI: 10.1002/qj.49710845502

Oke, T.R. 1987. Boundary Layer Climates $2^{\text {nd }}$ Ed., Methuen Co., London/New York.

Okoola, R.E. 1996. Space-time characteristics of the ITCZ over equatorial eastern Africa during anomalous rainfall years. PhD. Thesis, University of Nairobi, Kenya.

Okoola, R.E. 1999. A Diagnostic study of the Eastern Africa Monsoon Circulation during the Northern Hemisphere Spring Season. International Journal of Climatology, 19(2):143- 168. DOI: $\quad$ 10.1002/(SICI)1097-0088(199902)19:2<143::AIDJOC342>3.3.CO;2-L.

Ongoma, V., Muthama, N.J \& Gitau, W. 2013a. Evaluation of Urbanization Influences on Urban Winds of Kenyan Cities. Ethiopian Journal of Environmental Studies and Management, 6(3): 223 - 231. DOI: http://dx.doi.org/10.4314/ejesm.v6i3.1.

Ongoma, V., Muthama, N.J \& Gitau, W. 2013b. Evaluation of Urbanization Influences on Urban Temperature of Kenyan Cities. Global Meteorology, 2(1). DOI: http://dx.doi.org/10.4081/gm.2013.e1

Opijah, F.J., Mukabana, J.R \& Ng'ang'a, J.K. 2007. Rainfall Distribution over Nairobi area. Journal of Meteorology and Related Sciences, 1(1): 3-13. 
Peterson, T.C., Easterling, D.R., Karl, T.R., Groisman, P., Nicholls, N., Plummer, N., Torok, S., Auer, I., Boehm, R., Gullett, D., Vincent, L., Heino, R., Tuomenvirta, H., Mestre, O., Szentimrey, T., Salinger, J., Førland, E.J., Hanssen-Bauer, I., Alexandersson, H., Jones, P \& Parker D. 1998. Homogeneity adjustments of in situ atmospheric climate data: a review. International Journal of Climatology, 18(13): 1493-1517. doi: 10.1002/(SICI)1097-0088(19981115)18:13<1493::AID-JOC329>3.0.CO;2-T.

Rosenfeld, D \& Woodley, W.L. 2003. Closing the 50-year circle: from cloud seeding to space and back to climate change through precipitation physics. Chapter 6 of "Cloud systems, hurricanes, and the Tropical Rainfall Measuring Mission (TRMM)". In: Tao, Wei-Kuo, Adler, Robert (Eds.), 234 pp, AMS, Meteorological Monographs, 51: 5980

Rosenfeld, D., Dai, J., Yu, X., Yao, Z., Xu, X., Yang, X \& Du, C. 2007. Inverse relations between amounts of air pollution and orographic precipitation. Science, 315(5817):1396-1398. DOI: 10.1126/science.1137949

Shem, W \& Shepherd, J.M. 2008. On the impact of urbanization on summertime thunderstorms in Atlanta: two numerical model case studies. Atmospheric Research, 92(2): 172-189. doi:10.1016/j.atmosres.2008.09.013.

Shepherd, J.M., Pierce, H \& Negri, A.J. 2002. Rainfall Modification by Major Urban Areas: Observations from Spaceborne Rain Radar on the TRMM Satellite, Journal Applied Meteorology, 41(7): 689-701. doi: http://dx.doi.org/10.1175/15200450(2002)041<0689: RMBMUA> 2.0.CO;2.

Sneyers, R. 1990. On the Statistical Analysis of Series of Observations. WMO/TN- No. 143, WMO No. 415, Geneva.

Taha, H. 1994. Aircraft-based albedo measurements over South Coast Air Basin. In: Taha, T. (Ed), Analysis of Energy Efficiency of Air Quality in the South Coast Air BasinPhase II, Rep. No. LBL-35728, Lawrence Berkeley National Laboratory, Berkeley, CA, 1994, Ch. 2, pp. 43-59.

UNEP \& UN Habitat, 2011. Green Hills, Blue Cities, An Ecosystem Approach to Water Resources Management for African Cities. A Rapid Response Assessment. United Nations Environment Programme, GRID-Arendal. 11-14.

Unger, J. 1999. Comparisons of urban and rural bioclimatological conditions in the case of a Central-European city. International Journal of Biometeorology, 43(3):139-144. DOI: $10.1007 / \mathrm{s} 004840050129$ 
UN-Habitat, 2008. The State of African Cities; A Framework for Addressing Urban Challenges in Africa, UN Habitat, Nairobi.

Zhang, C.L., Chen, F., Miao, S.G., Li, Q.C., Xia, X.A \& Xuan, C.Y. 2009. Impacts of urban expansion and future green planting on summer precipitation in the Beijing metropolitan area. Journal of Geophysical Research, 114(D2). doi:10.1029/2008JD010328. 